the bowel and diarrhoa. It here seems that the clotting retards the too speedy production of peptone in bulk and thus assists in the support of the "coagulability theory," so that decalcification of milk would tend to produce "serous hæmorrhage" and defeat its own ends-that is, if the "serous hæmorrhage" theory of diarrhoea in infants is the only probable, possible, or likely factor. That matter is foreign to the object of this communication. Seeing, therefore, from the few and necessarily briefly discussed points, that there does exist a case against the proposed decalcification of milk, it would be of inestimable service to the general practitioner and others such as myself, who live in an atmosphere of outer misgiving, if those who have actual experience and deeper knowledge of these matters will kindly, if possible, demolish these few objections and clear the horizon to a more settled mode of procedure. Methods of predigestion and alteration of curd by enzymes such as diastase of malt in order to make it more easily assimilated, and an endeavour to assist and not deprive an infant of its 4"physiological" calcium phosphate, appear to commend themselves rather than a well-intentioned and unwitting decalcification of milk and infant too. Finally, it is an undoubted fact that calcium exerts a far more powerful trophic action on protoplasmic tissue otherwise than mere bone formation and pathological degeneration, as instanced its value in some conditions of blood destruction, tropical anæmia, strumous degenerations generally, glandular instability, \&c. Calcareous degeneration of ressels and tissue points apparently to defective tissue processes and deficient maintenance of physiological combination in situ than to mere chemical combination per se, as that of the silting up of sand at the mouth of a river. Calcium perhaps plays an anslogous part to the morphotic tissues that iron does to the oxygen-carrying power of red blood corpuscles. Defects of nutrition or perhaps deficiency, causing rickets, and mal-metabolism, carsing gout ; one condition leading to loss and the other to precipitation in situ. It now remains to hear a few words for the "defence" of decalcification of milk, so I conclude with every assurance of the mere desire to kindly and courteously criticise and discuss, and remain,

Sirs, yours faithfully,

F. W. Fonbes Ross, M.D.Etin.

Chepstow-place, W., Nor. 2nd, 1896.

\section{"POISONOUS HONEY."}

To the Editors of THE LANCET.

Sirs,-A few years ago I was poisoned by honey, and as the symptoms, though pretty severe, differed from those of your contributors it may interest your readers to have a brief history of my case. On Nov. 2nd, 1891, some honey which had been brought from the Isle of Wight two months previously was put on the breakfast table, and I ate a fair quantity of the honey that had fallen from the comb. I was at the time in perfect health, and with the exception of the honey my diet was precisely similar to what it had been for weeks. During the day I noticed that my thighs felt unusually warm and they were abnormally sensitive to touch. On undressing at night I observed that both thighs were covered with a bright-red smooth rash. Next morning I found that the rash had extended round the back and over the nates. Wherever the rash was there was considerable swelling, which pitted on pressure. Not suspecting the cause $I$ again ate the honey at breakfast. During the day the heat of the thighs increased, they were more swollen, and wherever the erythema was there was itching and pricking as from fine needles. The swelling and sensitiveness were much increased. I now suspected the honey as the cause of these symptoms, so did not eat any more. I found on inquiry that a large number of dead bees were taken from the honey that had escaped from the comb just before it was put on the table. The virus contained in the poison bags of these insects had evidently by exposure become mingled with the honey, and I was suffering from the pathogenic effects of bee-poison. I did nothing to interfere with the action of the poison and 'let the disease run its course. During the next six days the erythema, accompanied by cedema, continued to spread. On the third day there appeared bright red patches the size of my hand at the back of the upper arms and towards the scapulæ. The cedema of the thighs and legs increased greatly and it became uncomfortable to bend the knees on account of the swelling of the hams. The fourth day I felt some darting pains in the cardiac region and burning in the throat. On the afternoon of the fifth day I had a sudden attack of diarrhoa of liquid brown fæces and mucus attended by tenesmus. After this the erythema and cc dema gradually declined. The heat of the thighs gave place to horripilations over them, and intense itching of the discoloured cutaneous surface set in. The duration of the attack was about ten days, but even after three weeks the skin still remained discoloured where the erythema had been. I may mention that the eruption was absolutely symmetrical on both the lower and upper parts. The urine, with the exception of an occasional excess of urates, was normal during the whole period. My health in other respects continued good all the time. I made no alteration in my habits, walked about as much as usual, though the weight of my legs and the hide-bound feeling of the skin made walking not very pleasant. My appetite continued good and I took every morning a cold bath.

Montagu-square, Nov. 2nd. I am, Sirs, yours faithfully, R. E. DUDGEON.

\section{“THE LOSS OF LIFE FROM PREVENTABLE DISEASE."}

To the Editors of THE LANCET.

SrRs,--Since my last letter in The LANCET on the loss of life from whooping-cough, the most fatal of all the zymotic diseases of childhood under the age of fire years, a matter which all those interested in the progress of sanitary science deplore, my attention has again been directed to the subject. Some are in favour of notification and isolation, others recommending the education of parents as to the highly infectious and preventable nature of the malady by handbills and a system of house-to-house visitation by female inspectors. I am anxious to know from those of your readers who have given the latter method a trial what the result has been. With regard to allowing those suffering from the disease in a well-marked form to play in the streets of towns with healthy children and travel in public conreyances of various kinds there are few who would not condemn the practice, and it appears strange that our railway companies, especially so when they have a by-law in reference to the same, should take no action in the matter. We are forced to the conclusion that the school operation play an important part in the spread of the disease, and the question naturally arises to what extent this would be counteracted by a system of medical school inspection. I incline to the opinion that after recovery from pertussis disinfection is often neglected, and that one of the advantages obtained from notification, apart from isolation, would be the resulting proper and efficient disinfection. In many parishes blankets are given out to the poor for use during the winter months, which are washed and returned, but not, as a rule, disinfected.--I am, Sirs, yours truly,

St. Leonards, Nov. 6th, 1896. SAyUed LEe, M.D. St. And.

\section{THE WATER-SUPPLY OF MADEIRA.}

\section{To the Editors of THE LANCET.}

SIRS, - Letters commenting very adversely on the sanitary condition of Funchal, and especially as to its water-supply, having appeared in various English papers lately, we, the only resident and practising British medical men now here, consider it most desirable that the real state of the island should be published in detail. As regards the water-supply it has been stated that there is no drinking water in the town of Funchal except that conveyed in open and visibly polluted gutters to the drinking fountains of the town. Now this is not true. There is water conveyed to the town in open gutters or levadas, but this is solely for irrigation purposes and for flushing the drains; and although the poor inhabitants, too lazy or too ignorant to go further afield, constantly use this water for all domestic purposes with apparent impunity it has never been a source of drinking water supplied to visitors. The water for the principal drinking founts is conveyed from the mountains in iron pipes, not in open channels, and the sources are protected by buildings with locked doors and every precaution is taken to prevent contamination. There are founts of known good water and also some from suspected sources, but these are well known to every one and great discrimination is used. Also some of these founts have recently been connected with 
new springs and others are in progress of being so supplied. For many years past Madeira has been very free from zymotic disease, but after an unprecedented rainfail of between two and three times the average annual amount, and extending from September, 1894, to September, 1895, with only two summer months without rain, typhoid fever appeared in the season 1895 to 1896 . The water from the Joâo Diniz spring, from which the drinking water for all visitors and foreign residents was al ways orawn, has until last season been known to be good water both by analyses and long experience, and was consequently the last suspected. It was discovered last spring that this water had hecome fouled by leakage from a neighbouring drain. This unfortunate circumstance was sufficient to account for such illness as occurred here last season, which amounted to twenty-four of the visitors and residents being attacked with typhoid fever out of a total stated in the last consular report to be 2350 exclusive of foreign residents, and there were four fatal cases, only one of these being in presumably good health beforehand. The drrinage defect referred to has since been remedied temporarily, and the civil governor has stated this week that funds have come from Lisbon to thoroughly re-model the palace and other neighbouring drains.

In making these statements we do not in any wise wish to represent the water-supply of Madeira as being other than primitive and unsystematic or to do anything which could lead the authorities to consider the present arrangements at all adequate and not capable of great improvement. Meanwhile they have admitted the fact, and the town council have advertised for tenders for a complete water-supply to the town; also, the authorities at Lisbon have been petitioned to take off the duty on filters. All the hotels are now supplied with water filtered through PasteurChamberland filters, and most of them make their own soda-water from the same supply. All these reforms are subsequent to the outbreak last season. Pure ice from an English manufactory is abundantly available at a reasonable rate. The abattoirs are on a model that many English towns might copy to their advantage. The markets are excellent. The two largest dairies are managed with scrupulous care and cleanliness. In a matter of so much importance it is as useless as it is easy to publish Utopian schemes; but something more tangible and reassuring, both to medical minds and to the public, is required, and this, we trust, may be effected by our plain statement of facts as to the improved sanitary conditions here.

With an incomparable climate like that of Madeira, where a variation of $10^{\circ} \mathrm{F}$. shade temperature in the twenty-four hours is more than the average, and the extremes of summer shade and winter night temperature most rarely exceed $25^{\circ} \mathrm{F}$., with an excellent and pure food-supply, added to the fact that pure water $i s$ obtainable in all hotels and private houses, the conclusion arrived at cannot be other than that, so far from there being any danger to be apprehended from a residence in Madeira, the conditions of life here compare most farourably with those of the majority of known health resorts.

We are, Sirs, yours faithfully,

B. Rowley ('ONolly, M.R.C.S. Eng.,

Fredertck J. Hicks, M A., M.B. Oxon., \&c.

RONALD E. S. KRoHs, M.D. Lond., \&c.

Funchal, Madeira, Nov. 2nd, 1896.

THE committee of the Crickliow 11 Dispensary at their annual meeting held on the 31st ult. unanimously resolved to increase the salary of the medical officer, Mr. Philip E. Hill, M.R.C.S. Eng., from £25 to £35 per annum.

Bedford Medical SocteTy-A meeting of this society was held on Oct. 29th, the President. Dr. G. P. Goldsmith, being in the chair. Dr. Willmer Phillips read the notes of a case of Persistent Cough cured by the aspiration of a small quantity of pus from the chest. Dr. Willmer Phillips and Mr. Gifford Nash read notes of a case of Gangrene of the Lung treated by incision and drainage, which ended in recovery. Mr. Colby Sharpin read notes of a case of Ovariotomy for a Large Papillomatous Cyst, which was followed by the birth of a healthy child a year later. Mr. Kinsey showed a young man who was thrown from a bicycle on to a stake which entered the abdominal cavity. The gut which protruded was returned and the wound sutured, the patient recovering without a bad symptom. Dr. Rowland Coombs showed two Uterine Polypi and the Uterus and Appendages from a case of Carcinoma of the Body of the Uterus.
HOSPITAL ABUSE.

(By our Special Commissioner.)

IV.-LIVERPOOL. ${ }^{2}$

IT is freely acknowledged in Liverpool that medical men are now taking a greater interest in the question of hospital abuse than they did a few years back. On the other hand, my investigations so far tend to show that most of the hospital honorary physicians and surgeons do not think the grievance is very widespread. In any case the complaint, such as it is, is raised against the special rather than against the general hospitals. The parent hospital was erected in 1749 and was situated on the site now occupied by St. George's Hall. Public dispensaries were established after the hospital to meet a want which undoubtedly existed. The Liverpool Royal Infirmary was designed for in-patients. As ont-patients there were only cases of accidents and some of the old in-patients who occasionally returned for advice. Thus it was only natural that, apart from the hospital, there should be public charities called dispensaries for out-patients. These two systems were worked separately till within recent years. Now, however, the hospitals are gradually increasing their out-patients' departments; but the dispensaries still remain great institutions, and the number of their patients increases in spite of the action of the hospitais. There was no special sickness last year. The last annual report of the dispensaries states that the number of cases of infectious disease notified was 528 , which was about 300 less than the previous year; yet at the North, South, and East Dispensaries the total amount of patients seen was 56.742 in 1894 and 63,446 in 1895, thus showing an increase of 6704 for 1895 , in spite of the fact that the medical officer of health reports more favourably on the health of the town during the lattex of these two years. The same may be said of the patients treated at their own homes by the dispensary medical officers; these amounted for the three dispensaries to a total of 8288 in 1894 and to 9468 in 1896, an increase of 1180 patients. The total number of consultations given to all classes of patients by the public dispensary medical officers was 160,370 in 1894 and 175,283 in 1895, which is an increase of 14,913 , and represents for the latter year a daily average of 571 consultations. The question naturally arises whether out of this enormous number of patients there is not a considerable proportion who could well afford to pay for the advice of a private practitioner. The president of the managing committee, Mr. Meade-King, assures me that this is not so. If there is a grievance, he said, it is of the very opposite character. Medical relief is refused where, in the opinion of at least some people, it ought to be given. Patients who are in the receipt of outdoor Poor-law relief are referred back to the parish medical officer. It is argued that because a very poor person receives $2 s, 6 d$. a week from the parish or some loaves of bread that is no sufficient reason why such a person should not come to the dispensary. The treasurer, Mr. F. Bowden, related to me that some eight years ago members of the managing committee paid a surprise visit to the three dispensaries and made inquiries with regard to the patients who were then present. It became quite evident that there was no abuse at that moment. The addresses the patients gave, the houses and the streets in which they lived, sufficed to convince the committee of their extreme poverty. Also, the rule for the admission of patients states that " the only recognised patients of this institution are the sick poor who are unable to command the services of a regular practitioner, excepting in cases of accidents or other emergency, when relief in the first instance will be afforded to all who may require it. In no instance shall any case of midwifery be attended from the institution;" and, further, the rules state: "It is hoped that every subscriber will satisfy himself that the object of his recommendation is unable to pay for medicines as well as advice." It is acknowledged that occasionally it has been found that workmen earning as much as $27 s$. a week have come to the dispensary for advice. Such patients are

1 The previous articles on this subject were published in THE LANCET on the following dates: (1) Sept. 26th. 1896. Plymouth and Devonport (2) Oct. 10th. 1896, Exeter; (2 continued) Oct. 17th, 1896, Exeter (3) Oct. 31st, 1896, St. Thomas's Hospital, London. 